\title{
INCLUSÃO DE PESSOAS COM DEFICIÊNCIA NO ENSINO SUPERIOR: UMA REVISÃO INTEGRATIVA
}

\author{
INCLUSION OF PEOPLE WITH DISABILITIES IN HIGHER EDUCATION: AN \\ INTEGRATIVE REVIEW
}

\section{INCLUSIÓN DE PERSONAS CON DISCAPACIDAD EN LA ENSEÑANZA SUPERIOR: UNA REVISIÓN INTEGRATIVA}

Taynara Xavier Cruz ${ }^{1}$, Wellington Danilo Soares ${ }^{2}$, Raquel Schwenck Mello Vianna ${ }^{3}$

\begin{abstract}
RESUMO
Objetivo: analisar a produção científica sobre a inclusão de pessoas com deficiência no Ensino Superior por meio dos discursos dos discentes deficientes. Método: os dados foram coletados nas bases de dados LILACS, MEDLINE, Biblioteca Virtual SciELO, entre os anos 2014 a 2018, utilizando-se os descritores controlados Inclusão and Deficiência and Ensino Superior; Inclusão and Ensino Superior; Deficiência and Ensino Superior. A amostra final foi constituída por sete artigos selecionados após a análise dos títulos, resumos e textos na íntegra. Os artigos foram analisados de acordo com os eixos inserção e permanência. Resultados: os resultados demonstraram que o discente com deficiência ainda sente que as barreiras arquitetônicas e humanas são desfavoráveis à sua inclusão no Ensino Superior, tanto no ingresso quanto na permanência. Conclusões: nesta perspectiva, os próprios discentes sugerem mais divulgação e disseminação de aspectos legais sobre a inclusão, respeito e promoção de capacitação para os profissionais das mais diversas áreas do conhecimento.
\end{abstract}

Descritores: Pessoas com Deficiência; Ensino Superior; Estudante.

\section{ABSTRACT}

Objective: to analyze the scientific production on the inclusion of people with disabilities in Higher Education through the discourses of disabled students. Method: data was collected from the LILACS, MEDLINE, databases, Virtual Library SciELO, between the years 2014 and 2018, using the controlled descriptors Inclusion and Disability and Higher Education; Inclusion and Higher Education; Disability and Higher Education. The final sample consisted of seven articles selected after the analysis of titles, abstracts and texts

\footnotetext{
${ }^{1}$ Educadora Física. Universidade Federal dos Vales do Jequitinhonha e Mucuri/UFVJM. Teófilo Otoni (MG), Brasil.

${ }^{2}$ Doutor. Universidade Estadual de Montes Claros/UNIMONTES. Teófilo Otoni (MG), Brasil. ${ }^{3}$ Mestra (doutoranda). Universidad Catolica de Santa Fé/UCSF. Buenos Aires, Argentina.
}

Rev. Port. Saúde e Sociedade. 2019;4(1):1062 - 1075. 
in full. The articles were analyzed according to the insertion and permanence axes. Results: the results showed that disabled students still feel that architectural and human barriers are unfavorable to their inclusion in Higher Education, both in admission and in permanence. Conclusion: in this perspective, the students themselves suggest more promotion and dissemination of legal aspects on the inclusion, respect and promotion of training for professionals from several areas of knowledge.

Descriptors Disabled Persons; Education; Higher; Student.

\section{RESUMEN}

Objetivo: analizar la producción científica sobre la inclusión de personas con discapacidad en la Enseñanza Superior, a través de los discursos de los alumnos discapacitados. Método: los datos fueron recolectados en las bases de datos LILACS, MEDLINEL, Biblioteca Virtual SciELO entre los años 2014 a 2018, utilizando los descriptores controlados Inclusión and Discapacidad and Enseñanza Superior; Inclusión and Enseñanza Superior; Deficiencia and Enseñanza Superior. La muestra final fue constituida por siete artículos seleccionados después del análisis de los títulos, resúmenes y textos en su totalidad. Los artículos fueron analizados de acuerdo con los ejes inserción y permanencia. Resultados: los resultados demostraron que el alumno con discapacidad todavía siente que las barreras arquitectónicas y humanas son desfavorables a su inclusión en la Enseñanza Superior, tanto en el ingreso y en la permanencia. Conclusión: en esta perspectiva, los propios discentes sugieren más divulgación y diseminación de aspectos legales sobre la inclusión, respeto y promoción de capacitación para los profesionales de las más diversas áreas del conocimiento.

\section{Descriptores: Personas con Discapacidad; Educación Superior; Estudiante.}

\section{INTRODUÇÃO}

No Brasil, a Lei n 13.146/15, conhecida como Lei Brasileira de Inclusão, em seu Art. $2^{\circ}$, esclarece que pessoa com deficiência é "aquela que tem impedimento de longo prazo de natureza física, mental, intelectual ou sensorial, o qual, em interação com uma ou mais barreiras, pode obstruir sua participação plena e efetiva na sociedade em igualdade de condições com as demais pessoas."1

Nessa perspectiva conceitual, os dados trazem que, de acordo com o Censo de 2010, no Brasil, há 23,9\% da população total com algum tipo de deficiência, seja ela visual $(18,6 \%)$, auditiva $(5,1 \%)$, motora (7\%) ou mental/intelectual $(1,4 \%){ }^{2}$ Dessa maneira, pode-se notar que é um número considerável de pessoas que necessitam de alguma adaptação em seu cotidiano.

Ao pensar no cenário da educação brasileira, é notório ressaltar a quantidade de pessoas com deficiência matriculada nesses locais, uma vez que a legislação incentiva a matrícula de pessoas com deficiência em instituições de ensino regulares comuns (Declaração de Salamanca, Lei de Diretrizes e Bases da

Rev. Port. Saúde e Sociedade. 2019;4(1):1062 - 1075. 
Educação Nacional, Política Nacional de Educação Especial na Perspectiva da educação Inclusiva, etc.). . $^{3-5}$

Das pessoas com alguma deficiência, 14,15\% têm o Ensino Fundamental completo ou o Ensino Médio incompleto e apenas 6,66\% têm o nível superior completo. ${ }^{2}$ Dessa forma, é possível perceber a relação inversamente proporcional quanto ao número de pessoas com deficiência e o nível de instrução formal.

Com relação às legislações supracitadas dos direitos da pessoa com deficiência, no que tange à educação, salienta-se que a Declaração de Salamanca (1994) é considerada uma das bases documentais mundiais que visam à Educação Inclusiva. No Brasil, a Lei n 9.394, de 1996, estabelece as Diretrizes e Bases da Educação Nacional (LDBEN) e traz, em seu capítulo V, a definição de Educação Especial e a garantia do atendimento dos alunos com deficiência em salas de aula do ensino regular comum. ${ }^{4}$

No que concerne ao Ensino Superior, existem leis específicas que asseguram o ingresso e a permanência das pessoas com deficiência neste nível de ensino. Por exemplo, a Lei n 13.146, de julho de 2015 (Lei Brasileira de Inclusão), no Art. 30, garante medidas que devem ser adotadas para o ingresso e a permanência das pessoas com deficiência no Ensino Superior. Destacam-se provas em formatos acessíveis, recursos de acessibilidade e tecnologia, prolongamento de prazo de acordo com a demanda do aluno, tanto para a realização de provas para seleção quanto para atividades acadêmicas, entre outros. ${ }^{1}$ Além disso, a Portaria Normativa $n^{\circ}$ 9, de 5 de maio de 2017, certifica a garantia de vagas reservadas para pessoas com deficiência nas Instituições de Ensino Superior (IES). Importante salientar que ambas as leis visam a proporcionar a inclusão no Ensino Superior, como acesso e permanência. ${ }^{6}$

Soma-se a isso que alguns autores contextualizam que a inclusão das pessoas com deficiência não ocorre apenas com decretos e leis, mas necessita de uma mudança efetiva ao encarar os fatos e propor intervenções cabíveis para auxiliar no acesso e permanência no Ensino Superior. Dessa maneira, é necessário analisar como as leis estão sendo aplicadas nesse cenário e se de fato são adequadas. ${ }^{7}$

A partir de 1990, houve um discurso mais efetivo sobre as pessoas com Necessidades Educacionais Especiais (NEE). Assim, pode-se perceber um avanço político e social das causas defendidas. ${ }^{8}$ Desse modo, ao contextualizar esses avanços com o Ensino Superior, é notório ressaltar que, conforme os dados do

Rev. Port. Saúde e Sociedade. 2019;4(1):1062 - 1075. 
Censo da Educação Superior do Instituto Nacional de Estudos e Pesquisas Educacionais Anísio Teixeira (Inep), em um período de dez anos, entre 2004 e 2014, a admissão de pessoas com deficiência ao Ensino Superior teve um aumento significativo. Dessa maneira, é relevante considerar que as evoluções do marco legal, juntamente com as mudanças no cenário de inclusão de pessoas com deficiência na sociedade, auxiliaram o aumento efetivo desse número. No entanto, é importante destacar que há uma distinção entre o ingresso e a permanência e esta se torna fundamental na inclusão de pessoas com deficiência, uma vez que é necessário ter medidas de acessibilidade durante toda a trajetória acadêmica do indivíduo para garantir a efetiva inclusão. ${ }^{9}$

Dados do Censo da Educação Superior de 2016 verificaram um total de 37.927 matrículas de pessoas com deficiência, transtorno global do desenvolvimento ou altas habilidades declaradas. Esses números correspondem a 0,5\% em relação ao total de matrículas de graduação em $2015 .{ }^{10}$ Dentro dessa perspectiva, este estudo objetiva identificar, por meio da revisão integrativa, como ocorre a inclusão de pessoas com deficiência nas Instituições de Ensino Superior (IES), na visão dos discentes, no período de 2014 a 2018. A partir dos resultados, será possível promover uma discussão sobre a inserção e a permanência desse público, visto que já é comprovado que houve um aumento significativo dessas pessoas no Ensino Superior. Será analisado, a partir da literatura vigente, como está ocorrendo esta inserção, no olhar nos discentes.

\section{MÉTODO}

A revisão integrativa da literatura consiste em viabilizar conhecimentos produzidos sobre um dado problema e, após os resultados, possibilita a aplicação dos indícios na prática. ${ }^{11}$ Dado método, inicialmente, era utilizado para áreas da saúde para a produção de protocolos. Ao migrar esse tipo de pesquisa para a área da educação, tem-se a possibilidade de compreender melhor o que foi produzido sobre determinado tema e, assim, desenvolver possíveis conclusões/intervenções sobre este. ${ }^{12}$

Com o intuito de garantir a precisão metodológica do estudo, foram seguidas as seis etapas propostas pelos autores recém citados, sendo elas, respectivamente: estabelecer hipótese; buscar na literatura; classificar os

Rev. Port. Saúde e Sociedade. 2019;4(1):1062 - 1075. 
estudos; qualificar os estudos incluídos na revisão; elucidar os resultados e realizar a sinopse do conhecimento. ${ }^{11}$

A proposta deste estudo foi identificar, por meio da revisão integrativa, como ocorre a inclusão de pessoas com deficiência nas Instituições de Ensino Superior (IES), na visão dos discentes, no período de 2014 a 2018. Para tanto, foram utilizadas as seguintes bases de dados: Literatura Latino-Americana e do Caribe em Ciências da Saúde (LILACS); Biblioteca Virtual Scientific Electronic Library Online (SciELO) e na Publicações Médicas (MEDLINE). Utilizaram-se, nas buscas, as palavras-chave: Inclusão, Deficiência e Ensino Superior. Para auxiliar nas buscas, foi utilizado o modelador booleano "and".

Em decorrência da análise dos trabalhos, foram utilizados os seguintes critérios de inclusão: (1) artigos em que houvesse a temática da inclusão de pessoas com deficiência no Ensino Superior; (2) trabalhos que tratassem a visão do discente como a temática principal; (3) estudos produzidos entre os anos de 2014 a 2018; (4) periódicos com texto completo disponível on-line; (5) trabalhos realizados no Brasil; (6) artigos publicados no idioma português. Os critérios de exclusão foram: (1) artigos que tratassem de pessoas com necessidades especiais sem relação com a educação; (2) trabalhos que não foram realizados no período de janeiro de 2014 a novembro de 2018; (3) trabalhos que abordassem outro local fora da amplitude do Brasil; (4) artigos repetidos nas bases de dados; (5) artigos em outro idioma diferente do português;(6) trabalhos que não utilizassem a visão do discente como referência; (7) artigos que tratassem das deficiências específicas.

A pesquisa inicial foi realizada com a utilização das palavras Inclusão and Deficiência and Ensino Superior. Logo após, foi analisada a quantidade de trabalhos encontrados (72 artigos). Assim, dando sequência, a pesquisa foi filtrada nos seguintes quesitos: período de janeiro de 2014 a novembro de 2018; idioma português e apenas artigos. Foi analisada novamente a quantidade de trabalhos encontrados (34 artigos). Em seguida, foram verificados os títulos dos trabalhos para selecionar os mais aptos à demanda da revisão (16 artigos).

Na sequência, foi efetuada uma leitura dinâmica dos artigos selecionados para analisar o que os autores traziam no corpo de cada texto (seis artigos), quando houve seis artigos selecionados. Ao seguir o mesmo parâmetro, para ampliar a pesquisa, foram analisadas as seguintes palavras: Inclusão and Ensino

Rev. Port. Saúde e Sociedade. 2019;4(1):1062 - 1075. 
Superior. Desse modo, foi analisada a quantidade de trabalhos encontrados (327 artigos) e inseridos os critérios de exclusão (81 artigos).

Foram verificados os títulos dos trabalhos (14 artigos). Posteriormente, foi realizada a leitura dinâmica dos artigos (três artigos). Assim, não foi selecionado nenhum artigo. Somado a isso, também foram utilizadas, para a pesquisa, as palavras Deficiência and Ensino Superior, e analisado o total de trabalhos encontrados (101 artigos). Logo após, foram inseridos os critérios de exclusão (40 artigos) e efetuada a leitura dos temas (zero artigo). Assim, não houve artigo selecionado com essas palavras. Dessa maneira, posteriormente, as buscas resultaram em sete artigos selecionados para este estudo.

Para a construção do mapa mental, foi utilizado, como recurso, o software FreeMind (disponível gratuitamente

em: http://freemind.sourceforge.net/wiki/index.php/Download). Esse programa irá facilitar a visualização das estratégias de busca de dados e a apresentação dos mesmos.

\section{RESULTADOS}

A construção da amostra de dados analisados, descritos abaixo, está disposta no formato de mapa mental, apresentado na figura 1.

\section{Figura 1. Mapa mental}

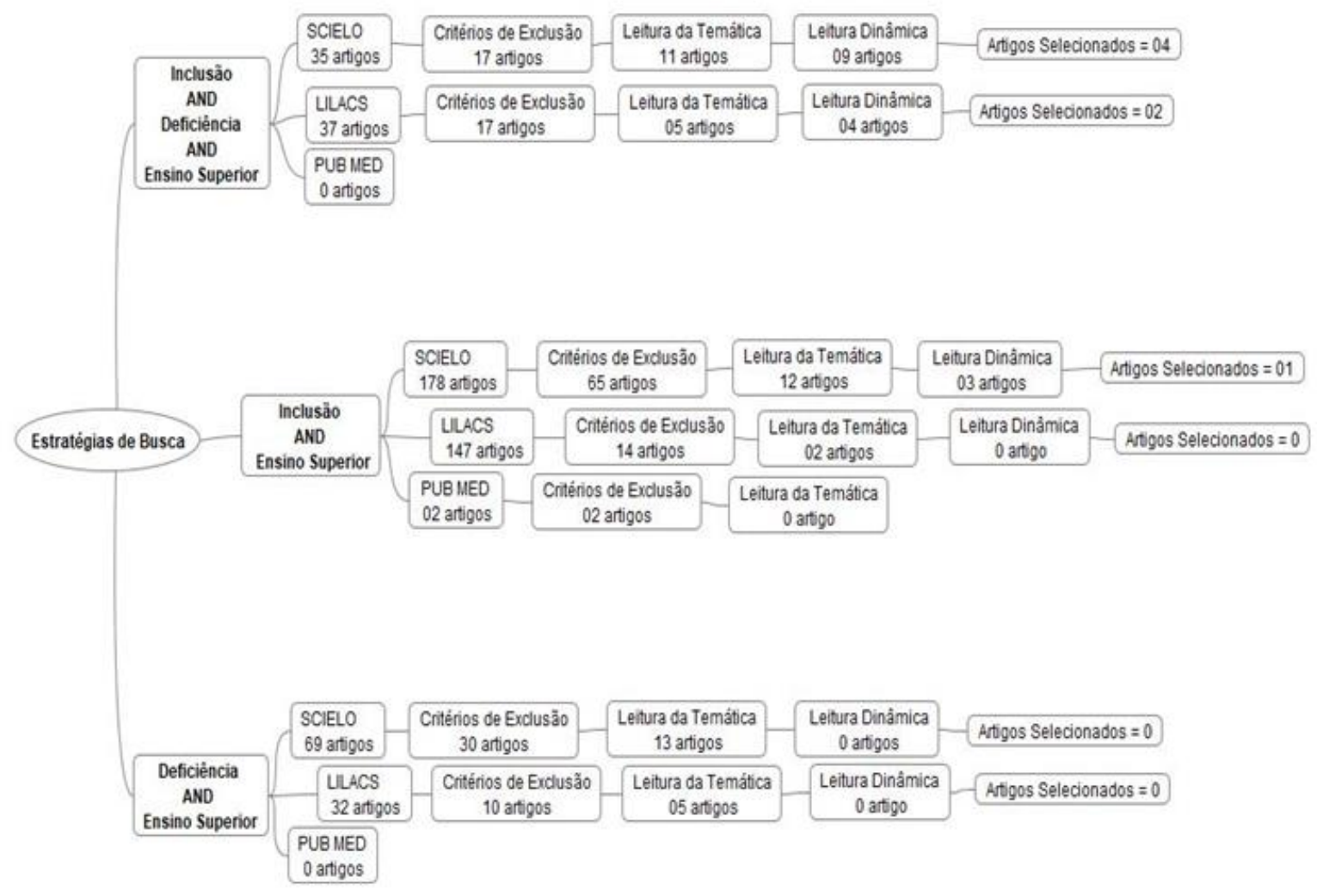


A partir da figura 1 e após as leituras dos artigos coletados, foi possível perceber que há poucos estudos que analisaram a visão dos discentes deficientes em relação ao acesso e à permanência dessas pessoas no Ensino Superior.

Após a primeira triagem, é notório ressaltar que, de 55 artigos, apenas 48 traziam como temática a inclusão de pessoas com deficiência no Ensino Superior. Destes, sete artigos relatavam a visão do discente como temática a ser abordada. Dessa maneira, ao analisar a amostra encontrada, pode-se perceber que cinco artigos foram encontrados na Biblioteca Virtual SciELO, dois artigos, na base de dados do LILACS e nenhum na base de dados MEDLINE.

Serão apresentados os dados referentes às análises dos materiais selecionados.

Tabela 1. Quantidade de publicações por ano.

\begin{tabular}{|c|c|c|}
\hline Ano de publicação & $\mathbf{N}$ & $\%$ \\
\hline 2014 & 1 & 14,28 \\
\hline 2015 & 0 & 0 \\
\hline 2016 & 1 & 14,28 \\
\hline 2017 & 1 & 14,28 \\
\hline 2018 & 4 & 57,14 \\
\hline Total & 07 & 100 \\
\hline
\end{tabular}

De acordo com a tabela 1, foi possível perceber que o ano de maior publicação de artigos com a temática de inclusão de pessoas com deficiência no Ensino Superior, na visão do discente, foi 2018, com 57,14\% da amostra total. Ainda foi possível depreender que, no ano de 2015, não houve nenhuma publicação na área.

Quanto à categoria do periódico dos artigos selecionados, obteve-se a tabela 2 abaixo.

Tabela 2. Categoria do periódico.

\begin{tabular}{lccc}
\hline & Qualis & N & \% \\
\hline A1 & & 2 & 28,57 \\
A2 & & 4 & 57,14 \\
B2 & 1 & 14,28 \\
\hline & Total & $\mathbf{0 7}$ & $\mathbf{1 0 0}$ \\
\hline
\end{tabular}

A tabela 2 demonstra que as pesquisas encontradas foram publicadas em periódicos de Qualis alto e todas indexadas, sendo a maioria dos estudos

Rev. Port. Saúde e Sociedade. 2019;4(1):1062 - 1075. 
(57,14\%), em periódicos de Qualis A2. Isso revela que as pesquisas estão tendo rigor metodológico e ético, demonstrando a verossimilhança com a realidade.

Com relação à categoria administrativa das instituições onde foram realizadas as pesquisas, obteve-se a tabela 3 .

Tabela 3. Categoria administrativa da instituição.

\begin{tabular}{lcc}
\hline \multicolumn{1}{c}{ Modelo } & $\mathbf{N}$ & \% \\
\hline Pública & 5 & 71,42 \\
Privada & 1 & 14,28 \\
Pública e privada & 1 & 14,28 \\
\hline \multicolumn{1}{r}{ Total } & $\mathbf{0 7}$ & $\mathbf{1 0 0}$ \\
\hline
\end{tabular}

A tabela 3 manifesta que 71,42\% dos trabalhos produzidos são referentes aos alunos de Instituições Públicas de Ensino Superior, contrapondo com 14,28\% de instituições privadas. Assim, é refletida uma maior presença das pessoas com deficiência nessa categoria de instituição. Nessa perspectiva e corroborando este fator, há o fato de as Instituições de Ensino Superior (IES) públicas terem, como tríade, o ensino, a pesquisa e a extensão; já as IES privadas têm somente o ensino.

A figura 2 traz informações gerais acerca dos artigos selecionados.

Figura 2. Informações gerais.

\begin{tabular}{|c|c|c|c|}
\hline Autor/Ano & Título & Objetivo & Conclusão \\
\hline $\begin{array}{l}\text { Guerreiro, } \\
\text { Almeida, Silva } \\
\text { Filho (2014) }\end{array}$ & $\begin{array}{lr}\text { Avaliação } & \text { da } \\
\text { Satisfação } & \text { do } \\
\text { Aluno } & \text { com } \\
\text { Deficiência } & \text { no } \\
\text { Ensino Superior }\end{array}$ & $\begin{array}{lr}\text { Identificar o nível de } \\
\text { satisfação dos alunos } \\
\text { quanto ao seu } \\
\text { acesso } & \text { e } \\
\text { permanência. } & \end{array}$ & $\begin{array}{l}\text { Não foi possível apresentar o } \\
\text { nível de satisfação. Porém, os } \\
\text { dados apontaram que os } \\
\text { fatores internos dos alunos } \\
\text { (psicoafetivos e atitudes) } \\
\text { podem colaborar com a } \\
\text { permanência do aluno na } \\
\text { instituição, juntamente com a } \\
\text { adequação dos meios } \\
\text { (estruturais e operacionais), } \\
\text { que foi alvo de bastante } \\
\text { insatisfação. }\end{array}$ \\
\hline $\begin{array}{l}\text { Calheiros, } \\
\text { Fumes (2016) }\end{array}$ & $\begin{array}{lr}\text { A inclusão } & \text { de } \\
\text { universitários } & \\
\text { com deficiência } \\
\text { em res r de } \\
\text { Cursos r rica } \\
\text { Educação } \\
\text { na cidade de } \\
\text { Maceió/AL } \\
\end{array}$ & \begin{tabular}{lr}
\multicolumn{2}{|l}{ Entender o processo } \\
de inclusão & de \\
universitários & com \\
deficiência em cursos \\
presenciais & de \\
graduação & em \\
Educação Física & na \\
cidade de Maceió/AL.
\end{tabular} & $\begin{array}{l}\text { A permanência dos alunos } \\
\text { está relacionada aos seus } \\
\text { próprios esforços e ao auxílio } \\
\text { de colegas de classe. } \\
\text { Inúmeras barreiras ainda são } \\
\text { presentes no espaço } \\
\text { educacional, deixando-os } \\
\text { mais vulneráveis à exclusão. }\end{array}$ \\
\hline $\begin{array}{l}\text { Berberian et } \\
\text { al. (2017) }\end{array}$ & $\begin{array}{l}\text { Inclusão } \\
\text { alunos }\end{array}$ & $\begin{array}{l}\text { Descrever e analisar } \\
\text { a visão de alunos }\end{array}$ & $\begin{array}{lll}\text { A inclusão } & \text { está } & \text { em } \\
\text { desenvolvimento, porém, há }\end{array}$ \\
\hline
\end{tabular}

Rev. Port. Saúde e Sociedade. 2019;4(1):1062 - 1075. 


\begin{tabular}{|c|c|c|c|}
\hline & $\begin{array}{ll}\text { deficiência } & \text { em } \\
\text { uma } & \\
\text { Universidade } & \\
\text { particular } & \text { de } \\
\text { Curitiba } & \\
\end{array}$ & $\begin{array}{l}\text { com deficiência } \\
\text { acerca de sua } \\
\text { experiência } \\
\text { acadêmica. }\end{array}$ & $\begin{array}{l}\text { algumas falhas para ser } \\
\text { supridas. Essas que deixam } \\
\text { os discentes deficientes } \\
\text { vulneráveis à exclusão. }\end{array}$ \\
\hline $\begin{array}{l}\text { Garcia, } \\
\text { Bacarin, } \\
\text { Leonardo } \\
(2018)\end{array}$ & $\begin{array}{lr}\text { Acessibilidade } & \text { e } \\
\text { permanência } & \text { na } \\
\text { educação } & \\
\text { superior: } & \\
\text { percepção } & \text { de } \\
\text { estudantes } & \text { com } \\
\text { deficiência } & \end{array}$ & $\begin{array}{l}\text { Analisar como os } \\
\text { alunos } \\
\text { deficiência de uma } \\
\text { Instituição Pública de } \\
\text { Educação Superior } \\
\text { percebem as reais } \\
\text { condições de acesso } \\
\text { e permanência na } \\
\text { universidade. }\end{array}$ & $\begin{array}{l}\text { No quesito tema, a instituição } \\
\text { está se adequando às } \\
\text { políticas públicas de inclusão, } \\
\text { de acordo com a demanda. } \\
\text { Porém, quanto à } \\
\text { acessibilidade, são } \\
\text { demonstradas limitações } \\
\text { quanto à permanência. }\end{array}$ \\
\hline $\begin{array}{l}\text { Anache, } \\
\text { Cavalcante } \\
\text { (2018) }\end{array}$ & $\begin{array}{lr}\text { Análise } & \text { das } \\
\text { condições } & \text { de } \\
\text { permanência } & \text { do } \\
\text { estudante } & \text { com } \\
\text { deficiência } & \text { na } \\
\text { Educação } & \\
\text { Superior } & \end{array}$ & $\begin{array}{lr}\text { Verificar } & \text { as } \\
\text { condições } & \text { de } \\
\text { permanência de } & \text { dadêmicos com } \\
\text { acadermon } & \text { deficiência em cursos } \\
\text { de educação superior } \\
\text { de uma instituição } \\
\text { federal. }\end{array}$ & $\begin{array}{l}\text { Alguns avanços foram } \\
\text { alcançados, no entanto, ainda } \\
\text { há necessidade de } \\
\text { investimentos } \\
\text { infraestrutura, mudança da } \\
\text { concepção do currículo, } \\
\text { formação dos professores e } \\
\text { demais profissionais e } \\
\text { informações para disseminar } \\
\text { a cultura da educação } \\
\text { inclusiva. }\end{array}$ \\
\hline $\begin{array}{l}\text { Almeida, } \\
\text { Ferreira } \\
\text { (2018) }\end{array}$ & $\begin{array}{lr}\text { Sentidos } & \text { da } \\
\text { inclusão } & \text { de } \\
\text { alunos } & \text { com } \\
\text { deficiência } & \text { na } \\
\text { educação } & \\
\text { superior: olhares } \\
\text { a partir } & \text { da } \\
\text { Universidade } & \\
\begin{array}{l}\text { Federal de } \\
\text { de Fora }\end{array} & \\
\end{array}$ & 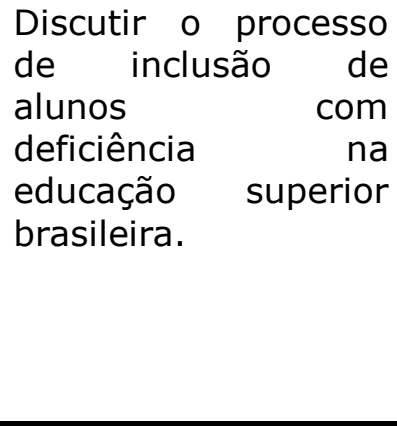 & $\begin{array}{l}\text { No sentido inclusão, há um } \\
\text { despreparo e } \\
\text { desconhecimento um } \\
\text { condições de permanência } \\
\text { dos alunos. Dessa maneira, } \\
\text { ocorrem empecilhos à sua } \\
\text { participação e condições de } \\
\text { igualdade na educação } \\
\text { superior. }\end{array}$ \\
\hline $\begin{array}{l}\text { Lourenço, } \\
\text { Battistella } \\
\text { (2018) }\end{array}$ & $\begin{array}{l}\text { Mapeamento de } \\
\text { alunos público- } \\
\text { alvo da educação } \\
\text { especial na } \\
\text { Universidade na } \\
\text { Federal de São } \\
\text { Carlos em 2014- } \\
2015\end{array}$ & $\begin{array}{lr}\text { Realizar } & 0 \\
\text { mapeamento } & \text { dos } \\
\text { estudantes } & \text { da } \\
\text { Educação Especial } & \text { nos cursos de } \\
\text { graduação r da } \\
\text { Universidade } & \text { Federal } \\
\text { de São Carlos. }\end{array}$ & $\begin{array}{l}\text { O estudo foi importante para } \\
\text { a universidade, pois trouxe } \\
\text { aspectos positivos quanto à } \\
\text { temática do acesso e à } \\
\text { permanência dos estudantes } \\
\text { da Educação Especial. Foi } \\
\text { relatada a questão do } \\
\text { preconceito que esses } \\
\text { estudantes sofrem, e que é } \\
\text { algo a ser trabalhado } \\
\text { diariamente no âmbito no } \\
\text { Ensino Superior, para que } \\
\text { esses tenham a sensação de } \\
\text { segurança. Assim, terão mais } \\
\text { facilidade de expor suas } \\
\text { necessidades e buscar seus } \\
\text { direitos. }\end{array}$ \\
\hline
\end{tabular}

Por meio das coletas dos dados, foi possível perceber que a maioria dos trabalhos produzidos sobre as pessoas com deficiência no Ensino Superior é

Rev. Port. Saúde e Sociedade. 2019;4(1):1062 - 1075. 
relativa à área da assistência na saúde, pois o número que relaciona esse público com o âmbito educacional é reduzido. Assim, é notório ressaltar que alguns autores ainda relacionam a pessoa com deficiência como condição de saúde, desvinculando, dessa forma, a discussão sobre a aproximação dessas pessoas com o contexto educacional.

Após os resultados apresentados, os mesmos serão analisados à luz da literatura e discutidos.

\section{DISCUSSION}

Este estudo teve como objetivo analisar a visão dos discentes com deficiência sobre a inserção e a permanência no Ensino Superior por meio de uma análise integrativa. Desse modo, após a leitura dos artigos encontrados, os resultados permitiram constatar que a inclusão de pessoas com deficiência no Ensino Superior está em constante evolução. No entanto, ainda há insatisfação, de modo geral, por parte dos alunos, o que dificulta o acesso e a permanência dos mesmos.

Pensar na inserção e na permanência da pessoa com deficiência no Ensino Superior é analisar duas condições básicas para obter uma formação acadêmica: o ingresso e a permanência. A primeira irá oferecer condições para a inserção e a segunda irá propor possibilidades para a continuidade e a formação. ${ }^{13}$ Após as leituras dos textos selecionados, foi perceptível que o acesso ao Ensino Superior é relatado apenas quando o vestibular é próprio da instituição. ${ }^{13-16}$ Não foi possível obter nenhum conhecimento, por meio do relato dos discentes, nos trabalhos analisados, sobre a acessibilidade no Sistema de Seleção Unificada (Sisu). Este é um sistema informatizado, gerenciado pelo Ministério da Educação (MEC), pelo qual instituições públicas de educação superior oferecem vagas a candidatos participantes do Exame Nacional do Ensino Médio (Enem).

Com relação ao ingresso de pessoas com deficiência no âmbito no Ensino Superior, alguns alunos demonstraram estar satisfeitos com a forma de inserção, enquanto outros relataram opiniões contrárias a esta. Alguns autores trazem, no corpo do seu texto, relatos de ingressantes com deficiência sobre a acessibilidade. ${ }^{13-15}$

Um estudo explicita que as pessoas que solicitaram atendimento especial nas provas de ingresso foram atendidas cada uma em sua especificidade, não havendo maiores problemas na realização dos exames. ${ }^{13}$

Rev. Port. Saúde e Sociedade. 2019;4(1):1062 - 1075. 
Dessa forma, pôde-se verificar que, em algumas instituições, os alunos com deficiência obtêm êxito ao solicitar atendimento especial, fator esse que auxilia diretamente o melhor acesso do indivíduo no Ensino Superior, visto que são disponibilizados recursos para que estes executem a prova de forma plural. No entanto, nem todos os alunos tiveram esse tipo de acesso.

Ainda quanto à acessibilidade para o ingresso da pessoa com deficiência, alguns pesquisadores salientam que "algumas faculdades não dão condições de terem intérpretes de Libras", 14:529 não havendo, muitas vezes, pessoas capacitadas para realizar a interpretação da Língua Portuguesa para a Língua Brasileira de Sinais e vice-versa.

De acordo com a pesquisa supracitada, não há, por vezes, condições plausíveis para realizar a prova, pois não há um profissional capacitado e fluente em Libras para traduzi-la. Assim, esse fato prejudica diretamente o desempenho do aluno durante a prova. Percebe-se, dessa maneira, a importância da capacitação de pessoal para o desempenho dessas funções.

Somado a isso, é notório ressaltar que, entre 2000 e 2010, houve um aumento de $933 \%$ de matrículas de pessoas com deficiência no Ensino Superior. No entanto, após as análises dos artigos, pode-se perceber que, em todos, há insatisfação no que diz a respeito à permanência dos discentes com deficiência no âmbito acadêmico, desse modo, sendo possível classificar duas barreiras pertinentes: a infraestrutura e os recursos pedagógicos. ${ }^{17}$

Ao relacionar a infraestrutura, em apenas uma universidade, os alunos estavam satisfeitos com os acessos arquitetônicos. ${ }^{15}$ Já, nas demais, a barreira arquitetônica estava presente de forma expressiva.

Podem-se perceber relatos como a falta de rampas, banheiros, pisos táteis, entre outros fatores acessíveis que interferem diretamente na mobilidade dos alunos. Alguns autores trazem essa questão bem clara nas falas dos próprios discentes, relatando que as normativas são somente praxe para o cumprimento de legislações, mas que, na prática, não há acessibilidade, além de relatos sobre o não funcionamento de elevadores e problemas no espaço para pessoas com mobilidade reduzida, como o uso de muletas. ${ }^{18}$

Nessa mesma vertente, alguns autores concluíram que a falta de infraestrutura é um fator prejudicial para a permanência dos alunos com deficiência. De acordo com alguns pesquisadores, as conjunturas de acessibilidade em uma instituição de ensino público federal ainda necessitam de

Rev. Port. Saúde e Sociedade. 2019;4(1):1062 - 1075. 
investimentos na infraestrutura. ${ }^{19}$ Outros autores destacam a insatisfação dos alunos em relação a fatores estruturais. ${ }^{20}$ Nessa mesma vertente, outros autores relatam que os entrevistados manifestaram falhas notórias sobre ações que se referem à acessibilidade arquitetônica. ${ }^{13}$

Desse modo, foi possível compreender que as barreiras arquitetônicas ainda são um empecilho para que os alunos com deficiência possam ter uma mobilidade satisfatória. Além disso, ainda há as barreiras pedagógicas que, na maioria das vezes, prejudicam os alunos nos conteúdos a serem aprendidos.

Nas pesquisas utilizadas, alguns discentes relataram a falta de preparação dos docentes quanto à forma de abordá-los e de estratégias de ensino coerentes com suas necessidades educacionais especiais. ${ }^{15}$ Neste contexto, ainda há a falta de profissionais que deveriam fazer esta intermediação entre o docente e o discente, como é o caso do tradutor-intérprete de Libras. Muitas vezes, o aluno, já matriculado, não tem o profissional para ajudá-lo, sendo necessário o uso da força da lei para tal. ${ }^{14}$

Além das falas dos discentes com deficiência, também há fragmentos dos autores que relatam a insatisfação dos alunos nas questões pedagógicas. Algumas pesquisas relatam que as barreiras atitudinais são expressas por meio do descaso entre outras ações provindas de professores, técnicos, gestores e colegas de turma. ${ }^{19}$ Assim, também, outros apresentam os aspectos pedagógicos como fragilizados e chegaram a essa conclusão após verificar as respostas dos participantes. ${ }^{15}$ Além disso, outros expressam a falta de disponibilidade e flexibilidade dos docentes ao se referir aos métodos avaliativos. ${ }^{16}$

\section{CONCLUSION}

Diante dos resultados apresentados, é evidente que o discente com deficiência ainda sente que as barreiras arquitetônicas e humanas são desfavoráveis à sua inclusão no Ensino Superior, tanto no ingresso quanto na permanência. Nesta perspectiva, os próprios discentes sugerem mais divulgação e disseminação de aspectos legais sobre a inclusão, respeito e promoção de capacitação para os profissionais das mais diversas áreas do conhecimento.

Além disso, ao visar a um avanço neste processo, sugere-se que as instituições ofereçam diferentes cursos que proporcionem diálogos sobre 0 contexto da deficiência e suas implicações para toda a comunidade acadêmica. Os dados aqui apresentados reforçam a importância de haver outros estudos

Rev. Port. Saúde e Sociedade. 2019;4(1):1062 - 1075. 
com maior amplitude envolvendo docentes, colegas de turmas e funcionários em

geral.

\section{REFERENCES}

1. Lei n. 13.146, de 6 de julho de 2015 (BR). Institui a Lei Brasileira de Inclusão da Pessoa com Deficiência (Estatuto da Pessoa com Deficiência). Diário Oficial da União [Internet]. 2015 [cited 2018 July 6]. Available from: http://www.planalto.gov.br/CCIVIL_03/_Ato2015-2018/2015/Lei/L13146.htm

2. Miinistério do Planejamento, Orçamento e Gestão (BR), Instituto Brasileiro de Geografia e Estatística. Banco de dados do Censo 2010 [Internet]. Rio de Janeiro: IBGE; 2010 [cited 2018 Apr 19]. Available from: https://censo2010.ibge.gov.br/

3. Organização das Nações Unidas para Educação, Ciência e Cultura. Declaração de Salamanca e Linha de Ação sobre Necessidades Educativas Especiais [Internet]. Brasília: UNESCO; 1994 [cited 2018 Aug 10]. Available from: http://portal.mec.gov.br/seesp/arquivos/pdf/salamanca.pdf

4. Lei n. 9.394, de 20 de dezembro de 1996 (BR). Estabelece as diretrizes e bases da educação nacional. Diário Oficinal da União [Internet]. 1996 [cited 2018 Dec 20]. Available from: http://www.planalto.gov.br/ccivil_03/LEIS/L9394.htm

5. Ministério da Educação (BR), Secretaria de Educação Continuada. Política Nacional de Educação Especial na Perspectiva da Educação Inclusiva [Internet]. Brasília Ministério da Educação; 2008 [cited 2018 Aug 10]. Available from: http://portal.mec.gov.br/index.php?option=com_docman\&view=download\&alias= 16690-politica-nacional-de-educacao-especial-na-perspectiva-da-educacaoinclusiva-05122014\&Itemid $=30192$

6. Ministério da Educação (BR), Gabinete do Ministro. Portaria Normativa n. 9 de 5 de maio de 2017. Altera a Portaria Normativa MEC n. 18, de 11 de outubro de 2012, e a Portaria Normativa MEC n. 21, de5 de novembro de 2012, e dá outras providências [Internet]. Brasília: Ministério da Educação; 2017 [cited 2018 Aug 10]. Available from: http://www.in.gov.br/materia//asset_publisher/Kujrw0TZC2Mb/content/id/20200505/do1-2017-05-08-portarianormativa-n-9-de-5-de-maio-de-2017-20200490

7. Rocha TB, Miranda TG. Access and stay of student with disabilities in higher education institution. Rev Educ Esp [Internet]. 2009 May/Aug [cited 2018 Aug 5]; 22(34):197-212. Available https://periodicos.ufsm.br/educacaoespecial/article/view/273/132

from:

8. Glat R, Pletsch MD. Fontes, Fontes RS. Inclusive education e special education: complementary propositions in the context of a school open to the diversity. Educação Santa Maria [Internet]. 2007 [cited 2018 Aug 10]; 32(2):343-56. Available from: https://periodicos.ufsm.br/reveducacao/article/view/678/487

9. Ministério da Educação (BR), Instituto Nacional de Estudos e Pesquisas Educacionais Anísio Teixeira, Secretária Executiva, Diretoria de Estatísticas Educacionais. Censo da Educação Superior 2014 [Internet]. Brasília: Ministério da Educação; 2014 [cited 2018 Aug 10]. Available from: http://download.inep.gov.br/download/superior/censo/2014/resumo_tecnico_cens o_educacao_superior_2014.pdf

Rev. Port. Saúde e Sociedade. 2019;4(1):1062 - 1075. 
10. Ministério da Educação (BR), Instituto Nacional de Estudos e Pesquisas Educacionais Anísio Teixeira. Censo da Educação Superior 2016 [Internet]. Brasília: Ministério da Educação; 2016 [cited 2018 Sept 10]. Available from: http://download.inep.gov.br/educacao_superior/censo_superior/documentos/201 6/notas_sobre_o_censo_da_educacao_superior_2016.pdf

11. Ercole FF, Melo LS, Alcoforado CLGC. Revisão integrativa versus revisão sistemática. REME Rev Min Enferm. 2014 Jan/Mar; 18(1):9-11. Doi: http://www.dx.doi.org/10.5935/1415-2762.20140001

12. Vosgerau DSAR, Romanowski JP. Review studies: conceptual and methodological implications. Rev Diálogo Educ. 2014 Jan/Apr; 14(41):165-89. Doi: 10.7213/dialogo.educ.14.041.DS08

13. Garcia RAB, Bacarin APS, Leonardo NST. Accessibility and permanence in higher education: perception of students with disabilities. Psicol Esc Educ. 2018; 22(Spe):33-40. Doi: http://dx.doi.org/10.1590/2175-3539/2018/035

14. Calheiros DS, Fumes NLF. The inclusion of students with disabilities in Physical Education underdegree courses in the city of Maceió-AL, Brazil. Avaliação (Campinas). 2016 July; 21(2):523-40. Doi: http://dx.doi.org/10.1590/S141440772016000200011

15. Berberian A, Krüger SI, Miranda BA, Guarinello AC, Costa LV, Silva DV, et al. Inclusion of students with disabilities in a particular university of Curitiba. Distúrb comun. 2017 Dec; 29(4):749-58. Doi: https://doi.org/10.23925/21762724.2017v29i4p749-758

16. Lourenço GF, Battistella J. Mapeamento de alunos público-alvo da educação especial na Universidade Federal de São Carlos em 2014-2015. Psicol Esc Educ. 2018; 22(Spe):25-32. Doi: http://dx.doi.org/10.1590/2175-35392018039

17. Governo do Brasil (BR). Matrículas de pessoas com deficiência em universidades cresceram 933\% em dez anos [Internet]. Brasília: Governo do Brasil; 2012 [cited 2019 Jan 15]. Available from: Matrículas de pessoas com deficiência em universidades cresceram $933 \%$ em dez anos

18. Almeida JGA, Ferreira EL. Sense of inclusion of students with disabilities in higher education: looks from the Federal University of Juiz de Fora. Psicol Esc Educ. 2018; 22(Spe):67-75. Doi: http://dx.doi.org/10.1590/2175$3539 / 2018 / 047$

19. Anache AA, Cavalcante LD. Analysis the conditions of the permanence of academics with disabilities in higher education. Psicol Esc Educ. 2018; 22(spe):115-25. Doi: http://dx.doi.org/10.1590/2175-35392018042

20. Guerreiro EMBR, Almeida MA, Silva Filho JH. Evaluation of satisfaction of disabled higher education students. Avaliação (Campinas). 2014 Mar; 19(1):31-60. Doi: http://dx.doi.org/10.1590/S1414-40772014000100003

Rev. Port. Saúde e Sociedade. 2019;4(1):1062 - 1075. 